\title{
The importance of safety in health communications
}

\author{
Brenda Lovell ${ }^{1}$, Raymond Lee ${ }^{2}$ \\ Independent, Winnipeg, Canada \\ University of Manitoba, Winnipeg, Canada
}

In our research study among Canadian physicians, we took a comprehensive look at health care communications, and the impact it can have on the physician-patient relationship. We were fortunate to have chosen suitable measures, which have provided us with insight on safety in health care communications [1].

While a number of published papers have examined health care communications, the relationships among safety, health communications and burnout in health professionals are not well understood. Katherine Miller in the 1990's published studies on the relationship between some aspects of communication and burnout, but little research has been published since. This paucity of research is due to the inherent conceptual and methodological differences found in interdisciplinary collaboration when studying the links among these variables.

Our research has raised three important question:

1. What is safe health care communications?

2. What are the associated risks to effective communications?

3. Why can communications pose risks?

In response to question 1) and based upon our findings, we propose the following definition: "Safe health care communications is when the best possible healthcare outcome has been formulated by minimizing possible risks to effective communication". In response to question 2), some of the risks highlighted in our study include physician burnout, years of practice, gender discordance, age and language barriers among others. In answer to question 3) we need to take into context a systemic problem that has been noted in American and European health care systems, that of insufficient time to spend with patients. To manage this problem, some Canadian family physicians have adopted a policy of "one diagnosis only per patient per visit" [2]. Effective interpersonal communications then becomes an important antidote to help prevent delayed diagnosis, and/or mistakes in diagnosis, and to support patients in managing their chronic diseases [3].

A critical issue that flows from our research is: how can risks to safety due to time constraints and one diagnosis per patient per visit be minimized? Many jurisdictions and health departments have recognized that enhanced public health policy is an important step. For example, the Swedish government 
is promoting a new plan to put people at the centre of public health policy [4]. They assert that tools for the individual and improvements in social conditions are needed to encourage patients to take on increased responsibility for their own health [4]. In the United States and other health systems, shared decision-making is receiving increased attention [5]. The European Commission has also conducted a qualitative study to start discussion on and to better understand the concepts of patient involvement in health care [6]. Communication was considered by many of the participants from the EU states as central to the concept of patient involvement [6]. Patients are also increasingly learning the tenets of good communication through grassroots patient health education and promotion programs [7].

Finally, our research team will be publishing in the near future, a meta analysis on some of the most important risks to physician burnout. It is hoped that with this information, interventions can be devised in combination with other nationwide policies and programs to support patient welfare, and more efficient health care systems.

\section{Acknowledgement}

An earlier discussion of this paper took place at the Wonca Europe Conference, Warsaw, Poland, September, 2011 attended by the second author.

\section{References}

1. Lovell BL, Lee RT, Brotheridge CM. Interpersonal factors affecting communication in clinical consultations-Canadian physicians' perspectives. International Journal of Health Care Quality Assurance 2012; 25: 467-82; http://dx.doi.org/10.1108/09526861211246430

2. Fullerton M. Understanding and improving on 1 problem per visit. CMAJ 2008; 179: 62; http:// dx.doi.org/10.1503/cmaj.081239

3. The impact of communication challenges on the delivery of quality health care to minority language clients and communities. Prince Edward Island French Language Health Services Network: Wellington, 2007. Available at www.santeipe.ca/userfiles/file/PositionPaper_FLHSN_EN.pdf(Last accessed September 2012)

4. Ministry of Health and Social Affairs, Government Offices of Sweden. Public Health policy with people at the centre. Stockholm, 2012. Available at http://www.regeringen.se/sb/d/15471/a/200182 (Last accessed October 2012)

5. National Academy for State Health Policy. Shared decision making: Advancing patient-centered care through state and federal implementation. Washington, DC, 2012. Available at http://www. nashp.org/publication/shared-decision-making-advancing-patient-centered-care-through-stateand-federal (Last accessed September 2012)

6. Director General for Health and Consumers. Patient Involvement. European Commission, May 2012. Available at: http://ec.europa.eu/health/healthcare/docs/eurobaro_patient_involvement_2012_en.pdf (Last accessed October 2012)

7. Merck \& Co, Inc. Communicating with health care practitioners. In: Beers MH, Jones TV (ed) 7884. Merck Manual of Health \& Aging. Whitehouse NJ: Merck Research Laboratories, 2004 